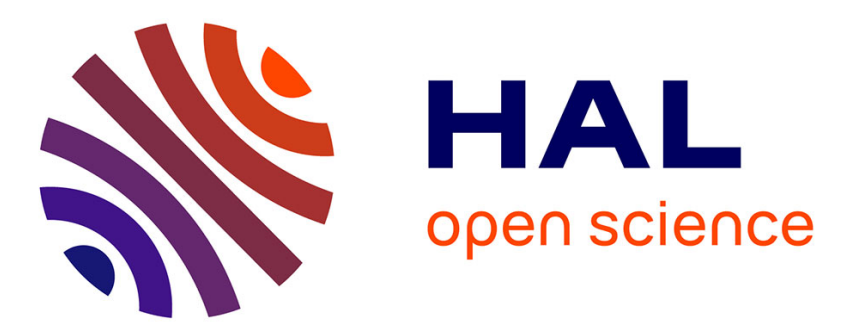

\title{
Application of 3S Techniques in the Study of Wetland Environment of Dong Ting Lake
}

Baicheng Xie, Chunxia Zhang, Xiqiang Shuai, Boliang Luo

\section{To cite this version:}

Baicheng Xie, Chunxia Zhang, Xiqiang Shuai, Boliang Luo. Application of 3S Techniques in the Study of Wetland Environment of Dong Ting Lake. Third IFIP TC 12 International Conference on Computer and Computing Technologies in Agriculture III (CCTA), Oct 2009, Beijing, China. pp.8-14, 10.1007/978-3-642-12220-0_2 . hal-01061715

\section{HAL Id: hal-01061715 https://hal.inria.fr/hal-01061715}

Submitted on 8 Sep 2014

HAL is a multi-disciplinary open access archive for the deposit and dissemination of scientific research documents, whether they are published or not. The documents may come from teaching and research institutions in France or abroad, or from public or private research centers.
L'archive ouverte pluridisciplinaire HAL, est destinée au dépôt et à la diffusion de documents scientifiques de niveau recherche, publiés ou non, émanant des établissements d'enseignement et de recherche français ou étrangers, des laboratoires publics ou privés. 


\title{
APPLICATION OF 3S TECHNIQUES IN THE STUDY OF WETLAND ENVIRONMENT OF DONG TING LAKE
}

\author{
Baicheng Xie ${ }^{1,{ }^{*}}$ Chunxia Zhang ${ }^{2}$ Xiqiang Shuai ${ }^{1}$ Boliang Luo ${ }^{1}$ \\ 1 Institute of Meteorology Science of Hunan Province ChangSha.Changsha Hunan province, \\ P. R. China 410007 \\ 2 Changsha Environmental Protetion College Changsha, Changsha Hunan province. P. R.
}

China 430023

* Corresponding author, Address: Institute of Meteorology Science of Hunan Province

ChangSha.Changsha Hunan province, P. R. China 410007, Tel: +86-731-85551337, Fax:

+86-731-85551337, Email: xbcyyhn@163.com

Abstract: Wetland is a multifunctional ecosystem in the earth, wetlands possess irreplaceable and enormous ecological functions and serve as an essential life supporting system. how to apply the new and high technology to the study of wetland has become the key point in wetland study area in our country. RS, GIS and GPS technology provide a new method for resource and ecological environment monitor. In this paper, the problem and development trend of $3 \mathrm{~S}$ technology are discussed. Application of $3 \mathrm{~S}$ technique in the study of wetland environment of Dongting Lake are described. The wetland monitor ways and technique route are introduced. The beach and water area information were gained.the dynamic changes of water were evaluated objective and quantitative. Finally, we point out the difficulties of wetland monitor of Dongting Lake.

Key words: Remote sensing system, Geographic information system,global position system Monitor of wetland, Dongting Lake 


\section{INTRODUCTION}

Wetland is a multifunctional ecosystem in the earth, In addition to providing extremely rich resources for human production and living, wetlands possess irreplaceable and enormous ecological functions and serve as an essential life supporting system. It is surrounded and converged biosphere; hydrosphere, geosphere and atmosphere. At the same time, all kinds of energy and substance are changed here. It is praised "the kidney of the earth" and "the heaven of avian". It is important for us to protect environment and biodiversity.

Wetland is a kind of crucial resource, natural landscape and unique ecosystem offering physical contribution to human society such as maintenance of biodiversity and water quality attenuation of floods and mitigation of extreme weather etc. (Mitsch and Gosse. Like, 1986; Lyon and Mccartby, 1995: Zhao eta1, 2003 ). The wetland area in china occupies 10 percent of the whole earth, however, with the environment pollution becoming worse, our country wetland area reduces gradually in recent years, In addition, and it leads to serious ecology consequence. So far, how to apply the new and high technology to the study of wetland has become the key point in wetland study area in our country. The study mainly includes the swamp and seashore resource survey and wetland exploitation.

Geographic Information Systems (GIS), Remote Sensing (RS) and Global Positioning Systems (GPS), which are often abbreviated to Three- $\mathrm{S}$ technologies in China, play significant roles in many extensive and integrated research related to space and time, and are valuable techniques and tools in obtaining, storing, managing, analyzing and visualizing ecological, water resource and socio-economic data for effective and efficient inventory and optimal policy and decision making(He and Jiang 1995; Zhu etal 2002).

Nowadays the development of the spatial information technology, the advanced technology and ways were supported for monitoring wetland. Studies on wetlands range from the spatial structures and functions to succession of wetlands at different levels(Yi, 1995; Wang et al, 2001). Recently many researchers are interested in the study of landscape patterns of wetlands based on RS and GIS at the landscape scale (Liu, 2004; Kelly, 2001 ). However, few studies can be reportedly erected the wetland information database and wetland information system, and how to share wetland information and deliver information mechanism also became research topics.

Three-S technologies often were applied in land use planning, land resource surveying, crop yield evaluating, disaster assessing, flood monitoring, fire preventing, and desertification controlling by interrelated research institutes, universities, and government sectors. However, little 
research has been devoted to the used of Three-S technologies in the field of wetland. With the human being understanding wetland of remote sensing deeply, the remote sensing expert classification and decision model base were erected, and wetland information can be automatic classification extraction. Wetland of remote sensing application will become a developing trend. In this paper three-S technologies were applied to ecology resource survey and wetland draft. How to erect the ecology information database will be introduced. It will supply reasonable suggestion for wetland exploiting, utilizing, protecting and making a long-term developing plan.

\section{MATERIALS AND METHODS}

\subsection{The situation of the Dong Ting Lake Wetland}

Located in the north of Hunan Province and the south bank of the Yangtze River middle reaches, the Dongting Lake is one of the five largest freshwater lakes and of the seven most important landscapes of internationally important wetlands in China. The Dongting Lake, as a typical water level regulator of the Yangtze River, receives four main rivers(namely the Xiang, the $\mathrm{Zi}$, the Yang, and the Li River)flowing through the Hunan Province, and the water of the three lake entrances of the Yangtze River. It is a buffers and plays a key role in aspects of tourism, irrigation, transportation, fishing, flood and drought controlling, climate regulation , drought controlling, beautifying environments and landscapes(Zhong, 1999).

There are $2740 \mathrm{~km}$ water area and $4080 \mathrm{~km}$ wetland area in the whole Dongting Lake region. It was separated into three parts, namely the South Dongting Lake, the East Dongting Lake and the West Dongting Lake, due to sedimentation and reclaiming lands in the lake. The Dongting Lake was selected as study area, which is located between $28^{\circ} 44^{\prime}-29^{\circ} 35^{\prime} \mathrm{N}$ and $111^{\circ} 53^{\prime}-113^{\circ} 05^{\prime} \mathrm{E}$. The main soil types are lake marshy soil and river marshy soil. The evaluation ranges from $35 \mathrm{~m}$ to $55 \mathrm{~m}$. its climate belongs to the transitional zone from the middle subtropical to north subtropical, with the precipitation from 1200 to $1550 \mathrm{~mm}$. Due to the reclamation of wetland, grassland and forestland on a large scale in traditional agricultural practices (terracing, overgrazing, woodcutting, cultivating fields, etc.), land use/cover had changed dramatically and the regional eco-environment had been rapidly deteriorating. The flood disaster raised awareness of the government and public for the importance of wetland conversation. Therefore, in 1994 the Chinese government signed the Ramsar Convention and designated Dongting Lake as wetland of International 
Importance. The Dongting Lake wetland is a national nature reserves in the study area, which are famous at home and abroad.

\subsection{The application of 3S technology}

The Three-S technologies were seldom employed in the research related to wetland in the 1980s, and they gained a wider appreciation in the late of 1990s. The Three-S technologies were used to the Wetland Resource Monitoring Centre in the first national wetland resource investigation. The Three-S technologies have great potentials in many kinds of research related to wetland. Land classification and changing detection techniques have been applying for mapping, investigation of wetland evolutionary process, landscape-change analyses, channel migration, flood, and wetlands resource monitoring. Spatial quantitative analyses and modeling are valuable methods in ecosystem service evaluation, wetland ecological process and risk assessment, wetland disease control, water quality monitoring and modeling, and wetlands hydrology.

Remote sensing can handle large amounts of input data and provide $s$ an effective and efficient means to describe the characteristics of a wetland system (Koneff \&Royle 2004) and its integral importance within watersheds and river basins. The Lake Institute in Nanjing used Landsate imagery to support the monitoring of the entry of sand and site into Poyang Lake (Zhao and Fu 2003) and Dongting Lake (Du et al.2001, Zhang et al. 1999) through analyzing the spectrum symbols, the landscape spectrum scenery and the living conditions of wetland floras in Sanjiang Plain, this paper found out the symbols of wetlands on remote sensing image, and established a series of classification models of remote sensing for different kinds of wetlands. The Guangdong wetland resources and environment information system (WREIS) was set up by the RS and GIS techniques (Huang, 1999). Areas inundated by floods and floodplains could be mapped effectively with remotely sensed data. The technology has been extensively used in the estimation of inundated area and the extent of flood damage along the Yellow River, Yangtza River, Huaihe River and many more basins (Zhang et al. 2003) .

The wetland is rich in plant landscape diversity: there are about 40 families, 75 genus and 131 species of the hydrophytes, of which wetland plants are an important part of the vegetation(The Department of Wild Animals and Plants, State Forestry Bureau of China,1996). It is especially important for us using the remote sensing technology to monitor great area wetland resource and eco-environment. Main applications are as follows: 1, using many wave bands is easier to distinguish land cover from vegetation 
style, namely, the land using and the style of wetland can be classified. 2, the soil surface moisture can be acquired from the shortwave infrared band data, thus, the boundary of scope and the change of area can be confirmed. 3, the vegetation cover information and the crop while is growing can be extracted from TM3 and TM4 band; the wetland style will be further classified. 4, the picture data can be overlaid the satellite images by vector superpose.

\subsection{Methods and Technology Route}

Wetlands are ecosystems typically found on the transition between terrestrial and aquatic systems. In order to be classified as a wetland, an area typically has at least one of the following three characteristics: first, there are a water table at or near the ground's surface during the growing season (including when the land is covered by shallow water); second, there are poorly drained or hydric soils; third, there is a unique diversity of wildlife and vegetation specifically adapted to thrive in wet environments. So far, there are a few researches in wetland bioloy diversity, wetland landscape pattern and how to define wetland boundry exactly. There are all kinds of wetland types in Dongting Lake, and the ecological environment is very complex, which is difficulty for us. First the rigions of wetland situation were suveryed, then classified systems of wetland are designed based on classification principal of international and investigation; second, we choose a proper waveband group, the image of TM being delt with, the style of wetland being determined; thrid, we use GPS to help locate in wetland investigation; Forth, the spots of image were determined, and drown; finally, the spots were digital; all of vector imformation will be imported from the GIS system.

We have collected the previous research ways about wetland remote monitor, and classified them. Finally, the wetland romote sensing monitor route will be established (Fig.1). We must get the wetland spectrum charactistic when the wetland are distinguised and classified. Because the substance spectrum characteritics are showed on the remote sensing image, at the same time, the spatial and time spectrum charactistic variety will be reavaled from it. The multi-temporal remote sensing information composition classification was chosen; such a way is mainly used to wetland spectral charactertic time effect. According to the vegetation living condition and the season difference, the multi-temporal images were compounded, then the wetland were divided into four types, such as, Bulrush wetland, Phalarideae wetland, Carex Montana wetland et al. 


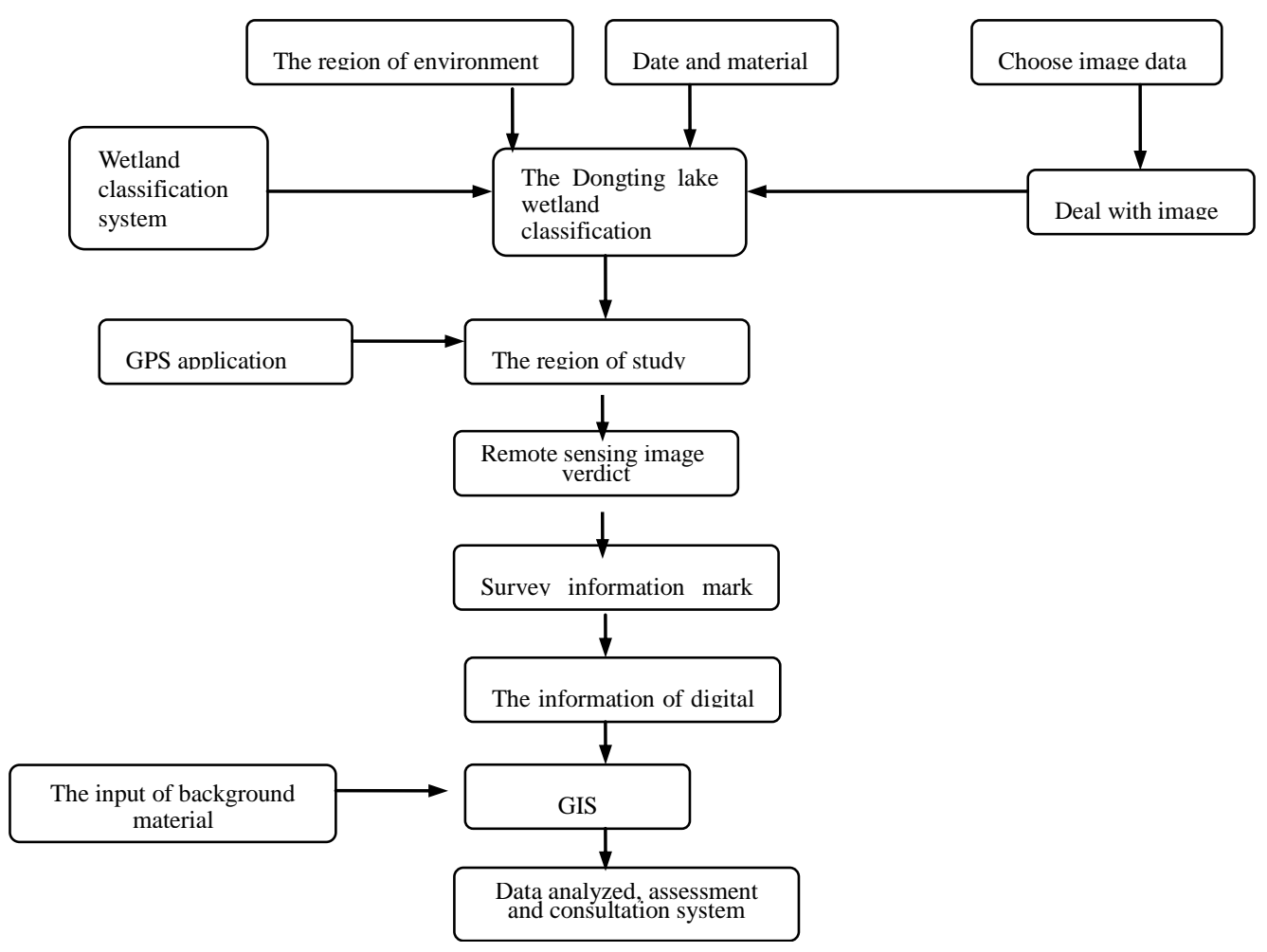

Figl. The route of Dongting lake wetland monitor technology

\section{RESULTS AND DISCUSSION}

The different period remote sensing data were applied for monitoring Dongting Lake wetland, the results showed that the different seasons have different water level, from the Fig 2 we can see that rich water seasons mainly is from May to September, the low water mainly concentrate from October to April. The minimum water area is $520 \mathrm{~km}^{2}$ in october 15, 2006 (Fig3), the maximum water area is $2503 \mathrm{~km}^{2}$ in September 15,2004 (Fig4).

Using the meteorological satellite to monitor the Dongting Lake water area, and caculate the water area, analytica the time and space changes Law.our government can make decides correctly by supplying the results when the flood is coming. Moreover, we can get great ecology environment law for monitoring the beach and water changes. 


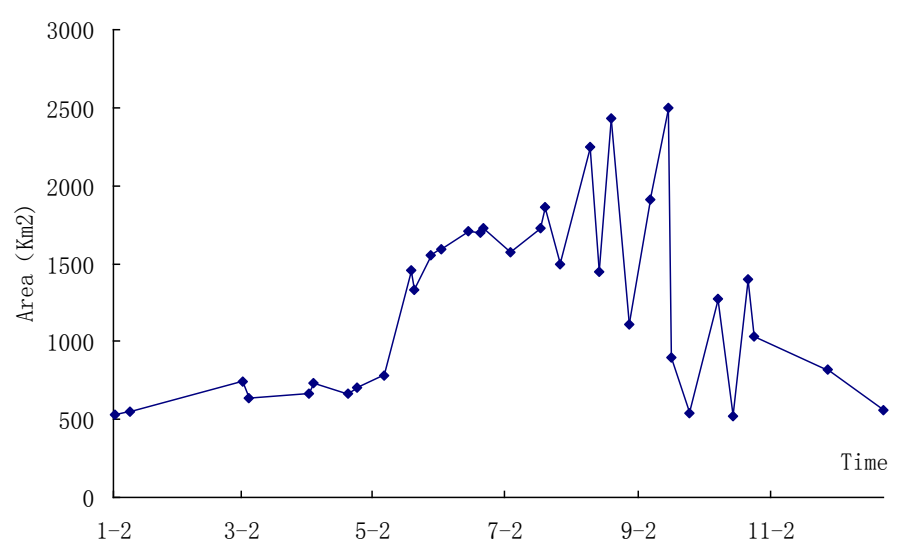

Fig2 The changes of water area in Dongting Lake from 2004 to 2006 yeatr

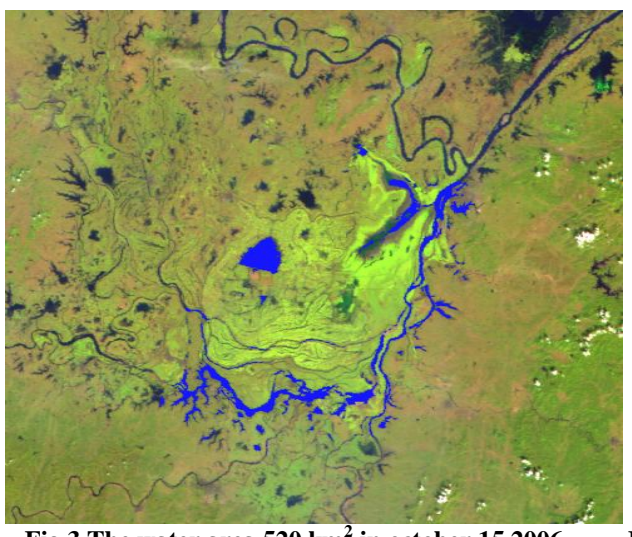

Fig 3 The water area $520 \mathrm{~km}^{2}$ in october 15,2006

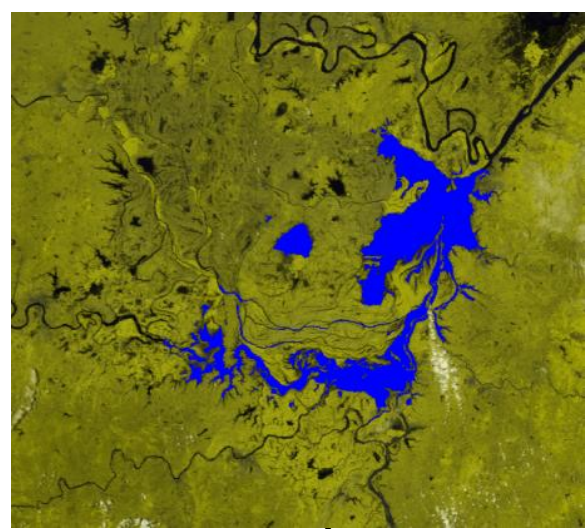

Fig4 The water area $2503 \mathrm{~km}^{2}$ in September 15,2004

\section{Problem and prospect}

The remote sensing technique and GIS technique have been applied extensively in wetland research, and it has solved many practical problems. But it cannot reach the sustainable development goal, many aspects need to be perfected and developedt further. First, there are obviously different wetlands spectral and other matter spectral on image, we can classify it. But some spectral character are similar to others types wetland spectral, it is very difficult for us to distinguish satellite image. Therefore, the wetland 
condition will be considered into wetland classification. Second, the water level of Dongting Lake has a big change in different seasons, which affects wetland dynamic monitor. Choosing the satellite image should consider the seasons because there are different results with abundant rainfall periods and low rainfall periods, it is possible to ensure the continuity of wetland variety. Third, The three-S technologies and ES will be integrated. The intelligent decision and support system can be erected. The utilization of peoplemachine-resource and the management integration, spatialization, intelligentization and visiblizaition can be realized; it is reference for reasonably making use of wetland resource. Forth, the many types of wetland information systems are erected based on Web system. Thus on the one hand it is likely to provide a large amount of wetland data, on the other hand, it will be provide people with the wetland science education for increasing people's consciousness of wetland protection.

\section{ACKNOWLEDGEMENTS}

Funding for this research was provided by china meteorological administration Department of Science and technique bureau (P. R. China). The first author is grateful to the whole member of project group for providing him with research ways at field survey in Dongting Lake.

\section{REFERENCES}

Yin Kangqian, Ni Jinren. Review of wetland studies, 1998,18(5): 539 546

Sun Guangyou, Development and prospect of wetland science in china, Acta Electronica sinaca 2000,15(6): 666 672

Zhang Shuqing, Chen Chun, Wan Enpu, A Study on wetland classifying of remote sensing in Sanjiang Plain, Remote Sensing technology and application, 1999,14(1): 54 58

Dou Hongshen,Jiang Jiahu, Dongting Lake, The Press of Science Technology University in China, $2000 \mathrm{HeHui}, 29 \mathrm{pp}$

Yuan Zhengke, The background data and resource database in Dongting Lake, 2001,7

Lyon J G, Cartby J M..Wetland and Environmental Applications of GIS, Lew is Publishers, NY, 1995

Huang Huiping, A Study on wetland resources and environment in Guangdong by GIS, Tropical Geography, 1999,19(2): 178 183

Wang Aihua, Zhang Shuqing,Zhang Bai, Application of Remote Sensing and Geographical Information System Technology to Wetland Research, 
WETLAND ENVIRONMENT OF DONTING LAKE

Remote Sensing technology and application, 2001,16(3):200 204

Zhang Bai, Application of Remote Sensing and Geographical Information System Technology to Wetland Research, Remote Sensing technology and application, 1996,11(1): 67 71

Huang Jinliang, The Area Change and Succession of Dongtinghu Wetland, Geographical Research, 1999,18(3): 297 304 